\title{
Perancangan Sistem Pengenalan Wajah Secara Real-Time pada CCTV dengan Metode Eigenface
}

\author{
Ardi Jamhari ${ }^{\# 1}$, Fahrudin Mukti Wibowo ${ }^{* 2}$, Wahyu Andi Saputra ${ }^{\# 3}$ \\ Fakultas Teknologi Industri dan Informatika, Institut Teknologi Telkom Purwokerto \\ Jln. D.I Panjaitan No 128, Purwokerto, Jawa Tengah, Indonesia \\ ${ }^{1} 15102050 @$ st3telkom.ac.id \\ ${ }^{2}$ fahrudin@ittelkom-pwt.ac.id \\ 33andi@ittelkom-pwt.ac.id
}

Accepted on 19-05-2020

\begin{abstract}
Abstrak
Perkembangan zaman serta rasa ingin tahu pada suatu kondisi menjadi alasan bagi orang untuk terus mengembangkan sistem keamanan pada rumah, salah satunya adalah dengan CCTV. Pada dasarnya sistem keamanan CCTV hanya berfungsi sebagai alat perekam tempat kejadian saja. Maka dari itu, tingkat keamanan dari CCTV masih rendah. Untuk itu diperlukan suatu sistem yang bisa menjadi solusi keamanan tersebut. Sistem dapat mendeteksi objek berupa wajah sebagai input citra. Untuk memasukan objek citra ke dalam sistem, sistem membutuhkan kamera. Objek yang terdeteksi oleh kamera, akan melakukan pencocokan wajah dengan gambar wajah yang terdapat pada class dataset. Sistem merupakan penerapan Computer Vision dalam sistem keamanan. Memori otak akan memberikan sebuah gambaran wajah yang pernah kita kenal sebelumnya. Analogi tersebut bisa diumpamakan sebagai sebuah mesin atau perangkat yang memiliki kemampuan sama seperti manusia untuk mengenal individu melalui citra wajah. Melalui penelitian ini akan dilakukan perbandingan pengenalan citra wajah dengan algoritma eigenface menggunakan ekstraksi fitur, PCA dan LDA yang diimplementasikan pada platform komputer secara real-time. Library yang digunakan dalam Eigenface adalah OpenCV. Tujuan dari penelitian ini untuk mengetahui metode mana yang memilki tingkat akurasi yang tinggi dalam melakukan pengenalan citra wajah dengan mambandingkan diantara kedua metode yang digunakan. Masalah yang dihadapi penulis ketika melakukan uji akurasi adalah tingkat cahaya yang berbeda antara dataset dan subjek uji coba, serta perubahan atribut seperti rambut dan janggut dapat mempengaruhi tingkat akurasi yang dihasilkan. Berdasarkan hasil pengujian diketahui bahwa akurasi yang dihasilkan eigenface PCA lebih baik dari eigenface LDA. Akurasi terbaik pada eigenface diperoleh dengan kombinasi PCA sebesar 98,06\%.
\end{abstract}

Keywords: Computer Vision, Ekstraksi Fitur Eigenface, Face Detection, Linear Discriminant Analysis, Principle Component Analysis 


\section{PENDAHULUAN}

B

iometrik merupakan karakter-karakter manusia yang dapat digunakan untuk membedakan antara

orang yang satu dengan yang lainnya. Dengan memanfaatkan karakter / organ tubuh yang ada pada setiap manusia untuk mengidentifikasi, misalnya wajah[1]. Selain itu terdapat karakteristik biometrik lainnya yaitu ucapan, sidik jari, dan retina.

Terdapat beberapa peneliti yang mengembangkan ilmu biometrik menjadi beragam metode untuk pengenalan wajah. Salah satu metode dalam pengenalan wajah dalam penelitian ini yaitu metode eigenface. Eigenface merupakan kumpulan dari eigenvector yang digunakan untuk masalah computer vision pada pengenalan wajah manusia. Eigenface dengan mencari nilai Eigen citra dan lain sebagainya. Dalam mendukung metode eigenface salah satunya dapat dilakukan ekstraksi ciri, ekstraksi ciri pun mempunyai metode - metode diantaranya metode PCA (Principle Component Analysis), SPCA (Simple Principle Component Analysis), LDA (Linear Discriminant Analysis) dan lainnya.[2] Adapun kelebihan LDA yaitu meminimumkan matrix covariance didalam obyek dan memaksimalkan matrix covariance antar obyek, tetapi metode LDA memiliki kekurangan yaitu metode LDA harus dikombinasikan dengan metode lain agar memberikan hasil yang lebih baik bila dibandingkan dengan penggunaan LDA saja. Metode ekstraksi fitur lainnya yaitu SPCA dimana kelebihan dari SPCA yaitu dapat melakukan penajaman citra pada proses pengenalan/identifikasi, tetapi SPCA harus dikombinasikan dengan metode euclidean agar dapat memberikan hasil yang maksimal.

Dalam kasus ini, metode pembanding yang digunakan yaitu LDA dan PCA. Dimana sistem pengenalan wajah eigenface dengan metode PCA, sistem mereduksi citra menjadi vektor ciri. Hal itu merupakan suatu kelebihan karena reduksi dimensi dapat dengan sendirinya melakukan transformasi linier dari suatu ruang berdimensi tinggi ke dalam suatu ruang yang berdimensi lebih rendah. Dan untuk menentukan dimensi yang lebih rendah dengan tingkat error yang minimum bisa dilakukaan dengan memilih jumlah nilai eigen terbesar dari ruang yang berdimensi tinggi tersebut. Selain kelebihan, metode ini juga memiliki kekukarangan yang dipengaruhi oleh perbedaan pencahayaan yang didapat antara citra test dan citra input. Sehingga komputasi yang dilakukannya pun akan menjadi lebih sedikit.

Ilmu biometrik mulai merambat pada perkembangan komputer, dimana ilmu tersebut terdapat pada suatu analisis citra yang disebut dengan computer vision. Computer vision adalah suatu pembelajaran menganalisis gambar dan video untuk memperoleh hasil sebagaimana yang bisa dilakukan manusia. Computer vision mencoba meniru cara kerja sistem visual manusia (Human Vision)[3]. Manusia melihat objek dengan indera penglihaan (mata), lalu citra objek diteruskan ke otak untuk diinterpretasi sehingga manusia mengerti objek apa yang tampak dalam pandangan matanya. Hasil interpretasi ini mungkin digunakan untuk pengambilan keputusan (misalnya menghindar kalau melihat mobil melaju di depan).

Sistem keamanan pada CCTV pada saat ini belum bisa menjamin keamanan rumah dengan maksimal, karena CCTV hanya bersifat merekam tidak menganalisis. Hal ini menjadikan CCTV hanya sebagai alat perekam tempat kejadian saja. Dari permasalahan tersebut pada penelitian ini akan dibuat sistem pengenalan wajah dengan metode Eigenfaces untuk keamanan rumah. Metode ini bekerja dengan cara mendeteksi ciri wajah seseorang, dan apabila wajah seseorang tersebut tidak ada di dalam database, maka secara otomatis sistem akan mengirim notifikasi berupa pop up notification yang akan muncul di layar komputer. Sehingga pihak keamanan bisa mengetahui kondisi rumah jika ada penyusup yang terdeteksi di kamera. Pada saat proses pengambilan citra dari kamera berlangsung, ada beberapa hal yang harus diperhatikan, seperti kondisi cahaya, variasi ekspresi, dan juga kualitas citra.

\section{TINJAUAN PUSTAKA}

Pada penelitian terdahulu, metode (Face Recognition) seperti Metode Eigenface, Metode Principal Component Analysis (PCA), dan Metode Local Binary Pattern Histogram (LBPH) telah banyak di gunakan untuk mengembangkan aplikasi keamanan biometrik diberbagai sektor. Salah satu sektor pengembangan 
aplikasi keamanan biometrik adalah pada sistem keamanan gedung dan rumah. Dalam penelitian ini, penulis berfokus kepada sistem keamanan rumah.

Derian dkk [1] melakukan penelitian untuk meningkatkan akurasi pengenalan wajah eigenface pada sistem untuk membuka pintu. Sistem dirancang dengan menggunakan bahasa pemrograman python dengan menggunakan Raspberry Pi, hal ini dirancang agar sistem bisa mencari sendiri posisi dari wajah di dalam sebuah citra. Hasil dari penelitian mengatakan pengenalan wajah berhasil, dan sistem akan mengirimkan sinyal berupa pulse kepada servo agar servo dapat berputar untuk membuka kunci.

Bagas dkk [2] melakukan penelitian pada CCTV gedung dan mengimplementasikan metode Eigenface dengan mengubah sudut kamera untuk mendapatkan tingkat akurasi yang optimal dalam pendeteksian wajah. Metode eigenface dalam penelitian tersebut, digunakan untuk proses mencocokkan objek wajah yang terdeteksi dengan wajah yang terdapat pada database. Hasil dari penelitian tersebut didapatkan bahwa Jarak optimal antara wajah dengan perangkat tidak lebih dari satu meter, untuk mendapatkan hasil yang baik.

Aris dkk [3] melakukan penelitian pada 6 jenis foto wajah yang berbeda dan dilakukan konversi citra dari format RGB menjadi grayscale. PCA digunakan sebagai pencari eigenface yang merupakan kumpulan dari vector eigen. PCA melakukan perhitungan matriks kovarian dari kumpulan citra wajah latih. Hasil dari penelitian tersebut adalah Pengenalan citra wajah dengan menggunakan metode PCA cukup berhasil. Sekitar 24 dari 30 data uji wajah berhasil dikenali dan sisanya 6 data wajah tidak dapat dikenali.

Tri dkk [4] melakukan penelitian dengan Menggabungkan dua metode Eigenface dan Jaringan syaraf Tiruan (JST) untuk mendapatkan akurasi pengenalan wajah yang maksimal. Eigenface digunakan untuk mereduksi dimensi ektor wajah menjadi ektor yang lebih sederhana (eigen vector). Hasil dari penggabungan metode eigenface dan JST dalam sistem pengenalan wajah memberikan hasil yang baik dengan tingkat pengenalan rata-rata $84,6 \%$.

Okkita dkk [5] melakukan penelitian mengembangkan perangkat lunak berupa aplikasi monitoring menggunakan CCTV untuk perangkat mobile berbasis Android. Penerapan ke perangkat mobile bertujuan untuk memudahkan untuk dibawa dan mengawasi dari jarak jauh. Hasil dari penelitian tersebut adalah Perancangan aplikasi mobile monitoring kamera CCTV untuk perangkat Mobile berbasis Android ini dapat membantu pengguna untuk melakukan pengawasan atau monitoring dari jarak jauh.

Dodit dkk [6] melakukan pengujian dengan metode eigenface PCA dan Adaboost pada sample wajah dengan beberapa jenis pengujian antara lain berdasarkan posisi, pencahayaan, jarak kamera, dan berdasarkan atribut berbeda (kumis, kacamata, model rambut dan jenggot). Penggunaan metode tersebut untuk pengenalan wajah pada kondisi real time dengan perbedaan jarak. Hasil dari penelitian tersebut diperoleh rata-rata tingkat keberhasilan pengenalan wajah dengan metode Adaboost dan Eigenfaces PCA mencapai 80\% pada berbagai kondisi berbeda (jarak objek dengan sensor, pencahayaan, posisi, atribut, dan mimik muka).

Eri dkk [7] penulis melakukan penelitian sistem pengenalan wajah dengan metode eigenface, dengan syarat obyek yang sama dengan perbedaan ekspresi dan pencahayaan harus dapat dikenali sebagai satu obyek yang sama. Hasil dari penelitian tersebut didapat Persentase keberhasilan pengenalan wajah objek citra berdasarkan ekspresi dari aplikasi yang dibuat adalah 86,67 persen. Keberhasilan sistem ini dalam mengenali wajah adalah 80 persen.

Harris dkk [8] melakukan perbandingan akurasi pengenalan wajah antara metode LBPH dan eigenface dalam mengenali tiga wajah sekaligus secara real-time. Hasil dari penelitian tersebut adalah metode LBPH lebih baik dalam mengenali 3 wajah sekaligus secara real time dibanding dengan metode Eigenface. Rata-rata akurasi pada pengujian pertama LBPH : 95.42\%, Eigenface : 57.50\%. Pengujian kedua LBPH : 97.09\%, Eigenface : $72.50 \%$.

\section{Metode PENELitian}

Tahapan yang akan dilakukan oleh peneliti dalam penelitian yang berjudul "Perancangan Sistem Pengenalan Wajah Secara Real-Time pada CCTV dengan Metode Eigenface", ditunjukkan pada gambar 3.1. 


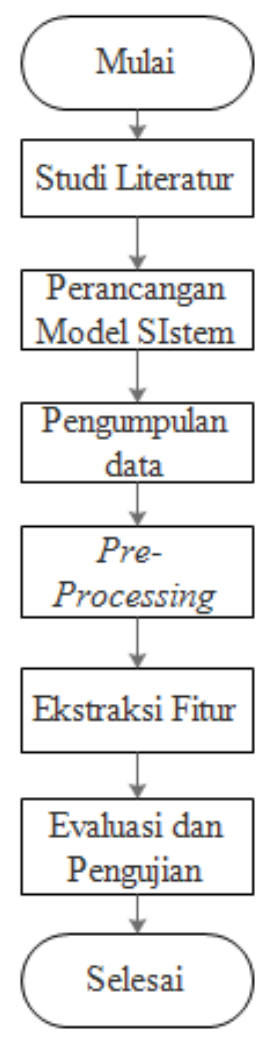

Gambar 3.1 Tahapan penelitian

\section{Studi Literatur}

Suatu penelitian harus didasari landasan teori yang kuat terkait masalah yang diteliti, sehingga apa yang dilakukan dapat dipertanggung jawabkan. Studi literatur digunakan sebagai landasan teori penelitian yang diperoleh dari buku referensi, jurnal, website, penelitian terdahulu, dan lain - lain.

\section{Perancangan model sistem}

UML ataua Unified Modeling Language yaitu suatu metode permodelan secara visual untuk sarana perancangan system berorientasi objek, atau definisi UML yaitu suatu bahasa yang sudah menjadi standar pada visualisasi, perancangan dan juga pendokumentasian sistem software. Saat ini UML sudah menjadi bahasa standar dalam penulisan blue print software. Dalam melakukan perancangan model sistem, penulis menggunakan UML serta prototype UI (User Interface) sebagai perancangan suatu sistem alur kerja sistem.

\section{Pengumpulan data}

Data yang dikumpulkan merupakan foto-foto wajah yang didapatkan dari wajah teman sekitar. Foto yang diambil memiliki ketentuan tertentu seperti wajah harus jelas terlihat, kualitas cahaya yang baik, dan berkualitas tinggi. Data tersebut akan dijadikan sebagai data training dan testing. Pengambilan data menggunakan fitur yang sudah dimodelkan di sistem, dan subjek hanya harus menghadapkan wajah ke kamera, dan sistem akan otomatis mendeteksi wajah dan mengambil gambar sesuai dengan jumlah dataset yang diperlukan. 


\section{4. $\quad$ Preprocessing}

Tujuan dari preprocessing adalah agar dataset diolah sehingga menghasilkan data yang sesuai dengan kebutuhan sistem. Pada tahap preprocessing terdapat 4 langkah yaitu konversi citra rgb menjadi grayscale, histogram equalization, reduksi noise pada citra, dan merubah citra 2D menjadi citra vector $1 \mathrm{D}$.

\section{Ekstraksi Fitur}

Tujuan dari ekstraksi fitur adalah mencari informasi-informasi yang merupakan ciri khusus dari setiap citra wajah. Pengambilan ciri pada database training melalui tahap penghitungan nilai eigenface dan PCA, sedangkan pengambilan ciri pada database test hanya melalui tahap penghitungan Evaluasi dan Pengujian

\section{Pengujian dan Ealuasi}

Tahapan pengujian dilakukan secara terstruktur, dari pengambilan sampel wajah, perhitungan vektor eigen, dan hasil akurasi. Pengujian dilakukan untuk memperoleh hasil. Untuk perhitungan tingkat akurasi akan digunakan proses perhitungan Accuracy, Precision dan Recall.

Confusion matrix merupakan sebuah metode yang biasa digunakan untuk melakukan pengukuran pada suatu classifier dalam melakukan prediksi dari kelas yang berbeda. Selain accuracy confusion matrix juga dapat menilai recall dan precision.

Model confussion matrix pada penelitian ini akan memiliki 4 nilai atau matrik $(2 \times 2)$. Berikut merupakan tabel 3.1 confusion matrix:

TABel 3.1 TABEl CONFUSSION MATRIX

\begin{tabular}{|c|c|c|c|}
\hline \multirow{2}{*}{\multicolumn{2}{|c|}{ Confussion Matrix }} & \multicolumn{2}{|c|}{ Nilai Sebenarnya } \\
\hline & & True & False \\
\hline \multirow[b]{2}{*}{ Nilai Prediksi } & True & $\begin{array}{l}\text { TP } \\
\text { (True Positive) } \\
\text { Correct Result }\end{array}$ & $\begin{array}{l}\text { FP } \\
\text { (False Positie) } \\
\text { Unexpected result }\end{array}$ \\
\hline & False & $\begin{array}{l}\text { FN } \\
\text { (False } \\
\text { Negative) } \\
\text { Missing Result }\end{array}$ & $\begin{array}{l}\text { TN } \\
\text { (True Negative) } \\
\text { Corect absence of } \\
\text { result }\end{array}$ \\
\hline
\end{tabular}

Precision didefinisikan sebagai rasio item relevan yang dipilih terhadap semua item yang terpilih. Precision merupakan probabilitas bahwa sebuah item yang dipilih adalah relevan.[9] Secara umum precision adalah tingkat ketepatan antara informasi yang diminta oleh pengguna dengan jawaban yang diberikan oleh sistem. Perhitungan precision dapat dilihat pada formula (3-1)

$$
\text { precision }=\frac{\text { True Positive }}{\text { True positive }+ \text { False Positive }}
$$

dengan True Positive = Jumlah banyaknya prediksi wajah yg benar dan False Positive = Jumlah banyaknya hasil prediksi wajah yang tidak terduga.

Sedangkan recall didefinisikan sebagai rasio dari item relevan yang dipilih terhadap total jumlah item relevan yang tersedia.[9] Perhitungan recall pada dasarnya merupakan perhitungan tingkat keberhasilan sistem dalam menemukan kembali sebuah informasi. Rumus perhitungan recall dapat dilihat pada formula (3-2) 


$$
\text { recall }=\frac{\text { True positive }}{\text { True positive }+ \text { False Negative }}
$$

dengan False Negative = Hasil yang tidak sesuai .

Accuracy didefinisikan sebagai tingkat kedekatan antara nilai prediksi dengan nilai aktual. Proses perhitungan accuracy dapat dilihat pada formula (3-3)

$$
\operatorname{accuracy}=\frac{T P+T N}{T P+T N+F P+F N}
$$

dengan True Negative $=$ Jumlah dataset yang ada di dalam sistem .

Evaluasi dilakukan pada sistem pengenalan wajah setelah dilakukan pengujian untuk mengetahui tingkat akurasi. Pada tahap ini, peneliti melakukan analisis dan mengolah data yang telah dikumpulkan dengan metode yang terkait. Hal tersebut dilakukan untuk perbaikan sistem yang dibangun.

\section{HASIL DAN PEMBAHASAN}

Dalam pengujian menggunakan klasifikasi Multi-layer Perceptron. Pengujian dilakukan sebanyak 2x per orang dengan interval waktu antara 1 hingga 3 menit tiap uji coba. Hasil uji coba dapat dilihat pada tabel 4.3 dan 4.4. Hasil pengujian Eigenface PCA dapat dilihat pada tabel 4.8

TABEL 4.1 HASIL PENGUJIAN PCA SAMPEL TANPA EKSPRESI

\begin{tabular}{|r|l|r|r|r|r|}
\hline \multicolumn{7}{|c|}{ PCA Wajah Datar } \\
\hline No & \multicolumn{1}{|c|}{$\begin{array}{c}\text { Sampel } \\
\text { Orang }\end{array}$} & $\mathbf{1}$ & $\begin{array}{c}\text { Waktu } \\
\text { (menit) }\end{array}$ & $\mathbf{2}$ & $\begin{array}{r}\text { Waktu } \\
\text { (menit) }\end{array}$ \\
\hline 1 & Ardi & TRUE & 2 & TRUE & 1 \\
\hline 2 & Reyhan & TRUE & 2 & TRUE & 1 \\
\hline 3 & Cahyo & TRUE & 1 & FALSE & 2 \\
\hline 4 & Iman & TRUE & 3 & TRUE & 2 \\
\hline 5 & Muti & TRUE & 1 & TRUE & 1 \\
\hline 6 & Nova & TRUE & 1 & TRUE & 1 \\
\hline 7 & Sean & TRUE & 2 & TRUE & 2 \\
\hline 8 & Wahyu & FALSE & 2 & FALSE & 3 \\
\hline 9 & Welly & TRUE & 1 & TRUE & 2 \\
\hline
\end{tabular}

Uji coba pada kondisi wajah datar menghasilkan nilai yang sangat tinggi. Dari 2 kali pengujian dan 18 kali pengambilan gambar, hanya 3 proses pengenalan wajah yang gagal atau menghasilkan prediksi yang tidak sesuai. Berikut hasil pengambilan gambar dengan hasil yang benar pada gambar 4.16 dan yang gagal pada gambar 4.17. pada gambar 4.16 sistem berhasil mengenali subjek bernama Ardi dengan benar. Sedangkan subjek bernama Wahyu, gagal dikenali oleh sistem. Kegagalan terjadi karena kondisi cahaya yang agak redup, dan dataset subjek tidak ada variasi ketika berada di cahaya yang redup. 


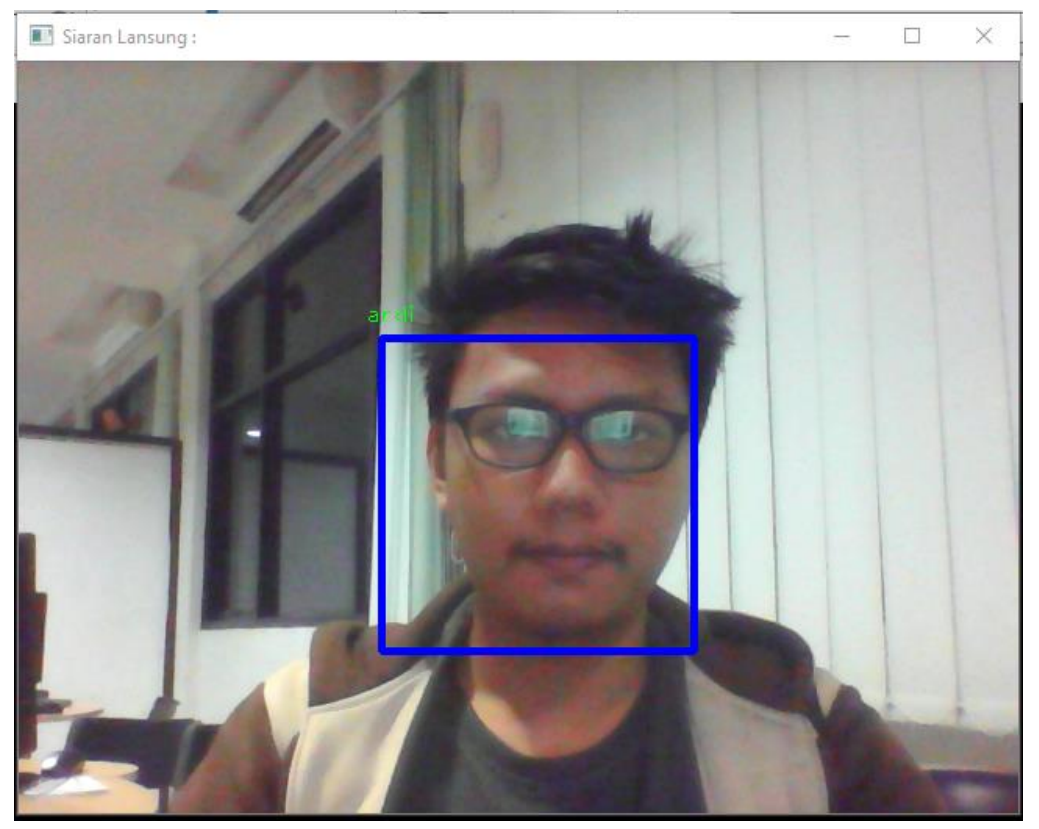

Gambar 4.1 Hasil uji coba PCA berhasil pada wajah datar

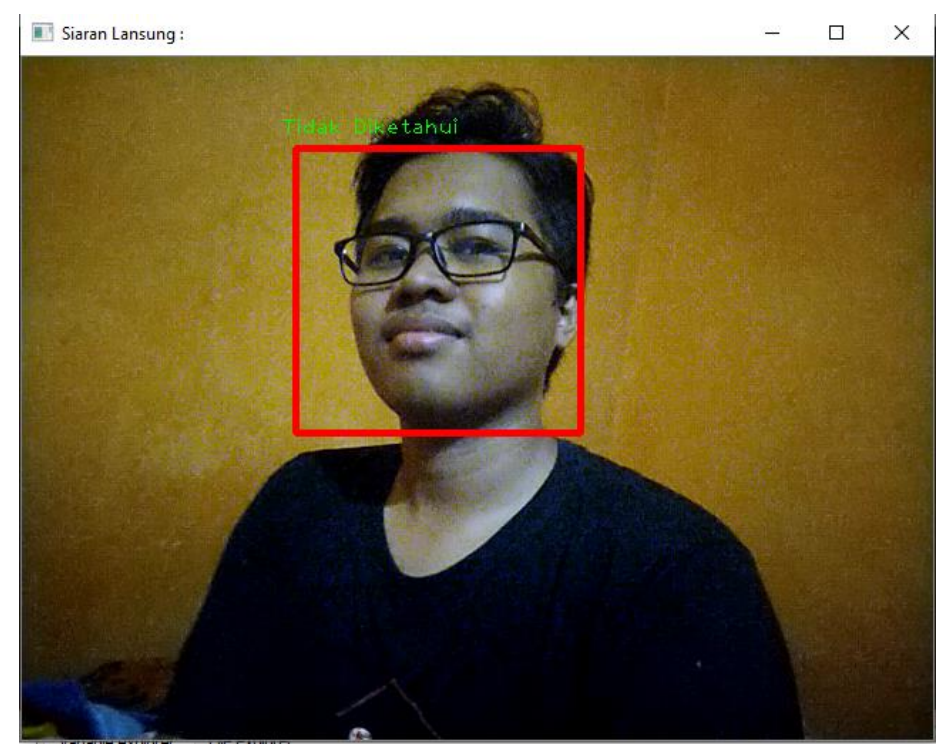

Gambar 4.2 Hasil uji coba PCA gagal pada wajah datar 
TABEL 4.2 HASIL PENGUJIAN PCA SAMPEL EKSPRESI SENYUM

\begin{tabular}{|r|l|c|r|c|r|}
\hline \multicolumn{7}{|c|}{ PCA Wajah Ekspresi Senyum } \\
\hline No & $\begin{array}{l}\text { Sampel } \\
\text { Orang }\end{array}$ & $\mathbf{1}$ & $\begin{array}{c}\text { Waktu } \\
\text { (menit) }\end{array}$ & \multicolumn{2}{c|}{$\begin{array}{c}\text { Waktu } \\
\text { (menit) }\end{array}$} \\
\hline 1 & Ardi & TRUE & 2 & FALSE & 1 \\
\hline 2 & Reyhan & FALSE & 2 & FALSE & 1 \\
\hline 3 & Cahyo & FALSE & 1 & FALSE & 1 \\
\hline 4 & Iman & FALSE & 3 & FALSE & 2 \\
\hline 5 & Muti & TRUE & 2 & TRUE & 1 \\
\hline 6 & Nova & TRUE & 3 & FALSE & 2 \\
\hline 7 & Sean & TRUE & 2 & TRUE & 1 \\
\hline 8 & Wahyu & TRUE & 2 & TRUE & 3 \\
\hline 9 & Welly & FALSE & 2 & FALSE & 1 \\
\hline
\end{tabular}

Uji coba pada wajah ekspresi senyum menghasilkan nilai yang kurang memuaskan. Hal ini dikarenakan kurangnya variasi dataset pada setiap kelas, membuat sistem sering mengalami kesalahan dan miss pada proses pengenalan wajah. Berikut hasil pengambilan gambar dengan hasil yang benar pada gambar 4.18 dan yang gagal pada gambar 4.19.

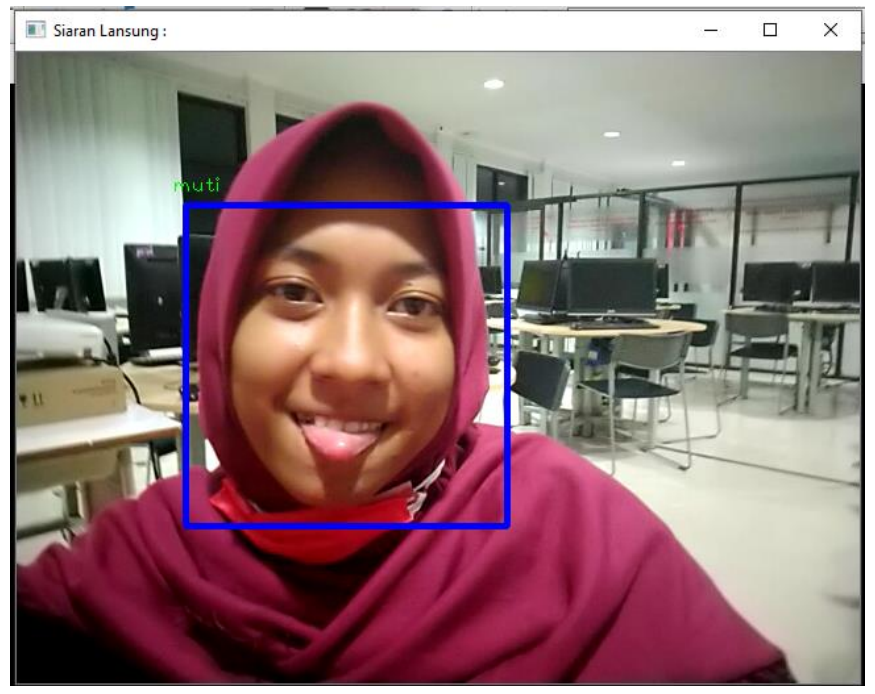

Gambar 4.3 Hasil uji coba PCA berhasil pada wajah senyum 


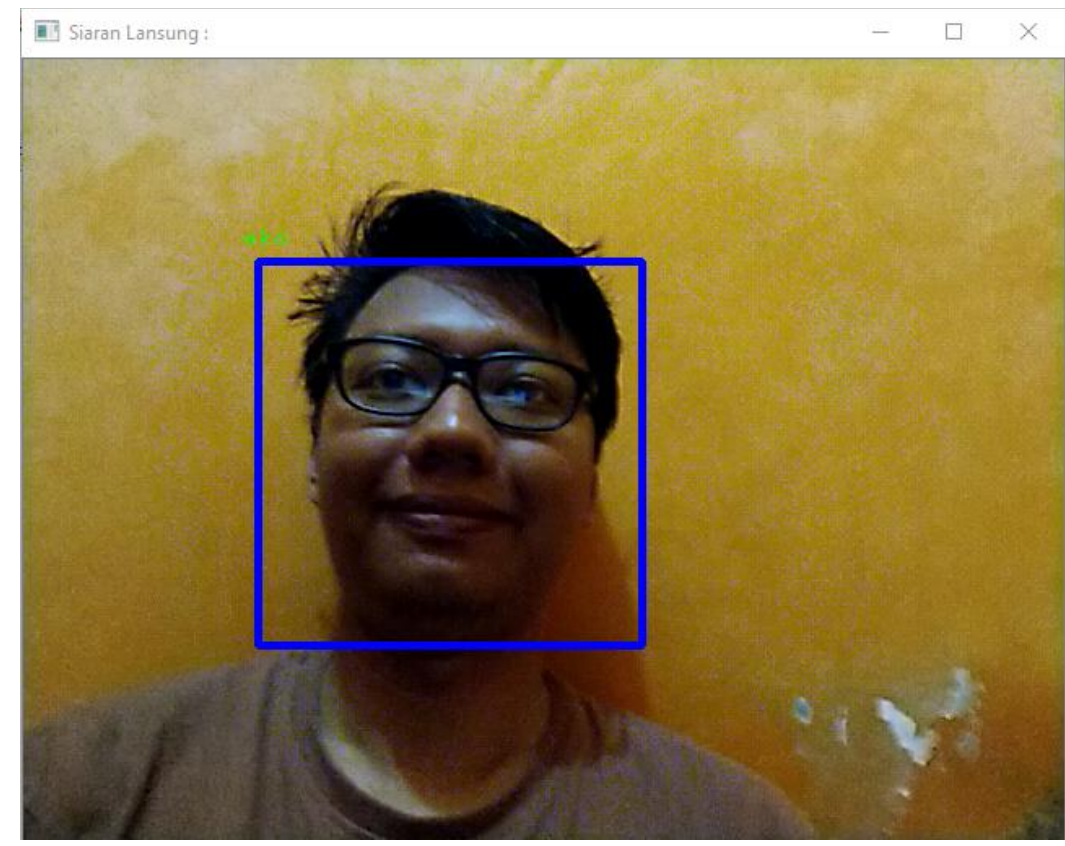

Gambar 4.4 Hasil uji coba PCA gagal pada wajah senyum

Langkah selanjutnya, melakukan pengujian dengan model LDA. Pengujian akurasi model LDA, dilakukan untuk mendapatkan akurasi terbaik. Dalam pengujian tersebut menggunakan klasifikasi Multi-layer Perceptron dapat dilihat pada tabel 4.5

TABEL 4.3 HASIL PENGUJIAN LDA SAMPEL TANPA EKSPRESI

\begin{tabular}{|r|l|c|r|c|r|}
\hline \multicolumn{7}{|c|}{ LDA Wajah Datar } \\
\hline No & $\begin{array}{c}\text { Sampel } \\
\text { Orang }\end{array}$ & $\mathbf{1}$ & $\begin{array}{c}\text { Waktu } \\
\text { (menit) }\end{array}$ & $\mathbf{2}$ & $\begin{array}{c}\text { Waktu } \\
\text { (menit) }\end{array}$ \\
\hline 1 & Ardi & TRUE & 2 & FALSE & 3 \\
\hline 2 & Reyhan & FALSE & 3 & FALSE & 2 \\
\hline 3 & Cahyo & TRUE & 1 & TRUE & 2 \\
\hline 4 & Iman & TRUE & 2 & TRUE & 3 \\
\hline 5 & Muti & TRUE & 1 & TRUE & 1 \\
\hline 6 & Nova & FALSE & 2 & FALSE & 3 \\
\hline 7 & Sean & TRUE & 3 & TRUE & 2 \\
\hline 8 & Wahyu & FALSE & 2 & FALSE & 3 \\
\hline 9 & Welly & TRUE & 1 & TRUE & 1 \\
\hline
\end{tabular}

Pada pengujian dengan ekstraksi fitur LDA, hasil pengenalan yang dihasilkan pada pengujian wajah datar dan wajah senyum menghasilkan perbandingan yang tidak signifikan, dengan jumlah kesalah prediksi yang tidak berbeda jauh. Namun, LDA sering melakukan kesalahan dalam mengenali wajah pada subjek yang telah merubah atribut pada wajah, seperti memakai kacamata, dan mengubah gaya rambut menjadi lebih pendek. Seperti hasil pengenalan pada gambar 4.21 subjek mencukur rambut hingga berbeda dengan yang ada di dataset. mengakibatkan sistem melakukan kesalahan ketika melakukan pengenalan wajah. 


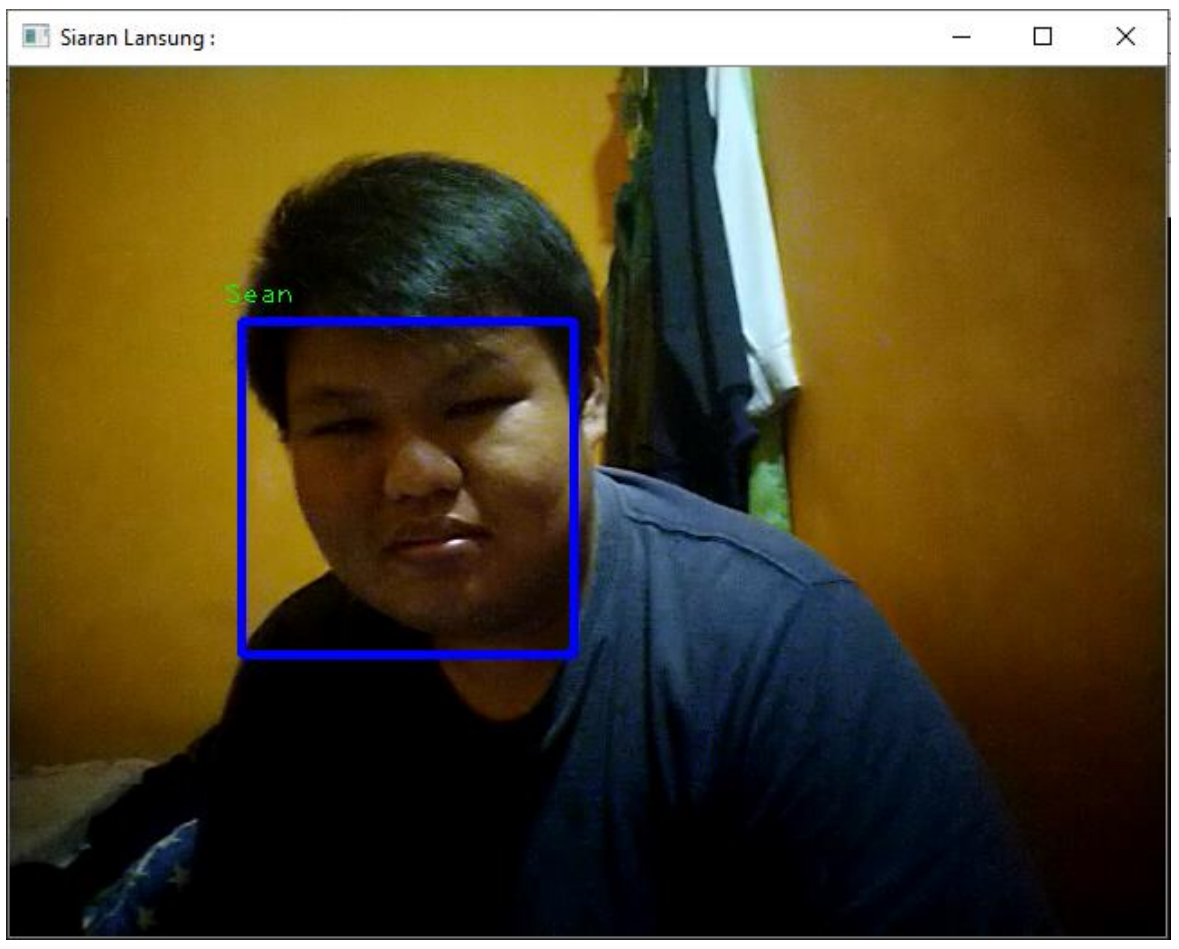

Gambar 4.5 Hasil uji coba LDA berhasil pada wajah datar

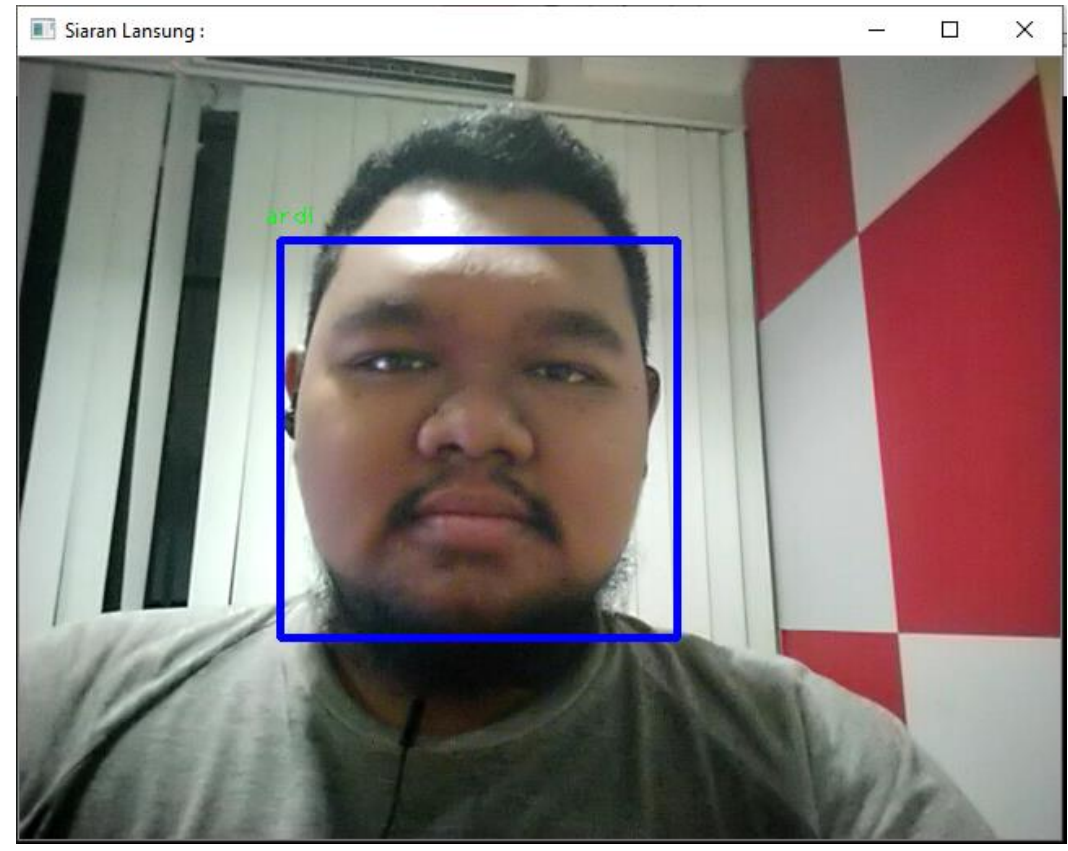

Gambar 4.6 hasil uji coba LDA gagal pada wajah datar 
TABEL 4.4 HASIL PENGUJIAN LDA SAMPEL EKSPRESI SENYUM

\begin{tabular}{|r|l|c|r|c|r|}
\hline \multicolumn{7}{|c|}{ LDA Wajah Ekspresi Senyum } \\
\hline No & $\begin{array}{c}\text { Sampel } \\
\text { Orang }\end{array}$ & $\mathbf{1}$ & $\begin{array}{c}\text { Waktu } \\
\text { (menit) }\end{array}$ & $\mathbf{2}$ & $\begin{array}{c}\text { Waktu } \\
\text { (menit) }\end{array}$ \\
\hline 1 & Ardi & TRUE & 2 & TRUE & 3 \\
\hline 2 & Reyhan & FALSE & 2 & FALSE & 2 \\
\hline 3 & Cahyo & TRUE & 1 & FALSE & 2 \\
\hline 4 & Iman & TRUE & 1 & FALSE & 2 \\
\hline 5 & Muti & TRUE & 1 & TRUE & 1 \\
\hline 6 & Nova & TRUE & 2 & TRUE & 2 \\
\hline 7 & Sean & TRUE & 2 & TRUE & 2 \\
\hline 8 & Wahyu & FALSE & 3 & FALSE & 3 \\
\hline 9 & Welly & FALSE & 2 & FALSE & 2 \\
\hline
\end{tabular}

Pada pengujian pada wajah senyum, sistem sering mengalami kesulitan dalam mengenali wajah ketika subjek mencoba mempertahankan eksoresi wajah senyum. Hasil prediksi gagal dapat dilihat pada gambar 4.22.

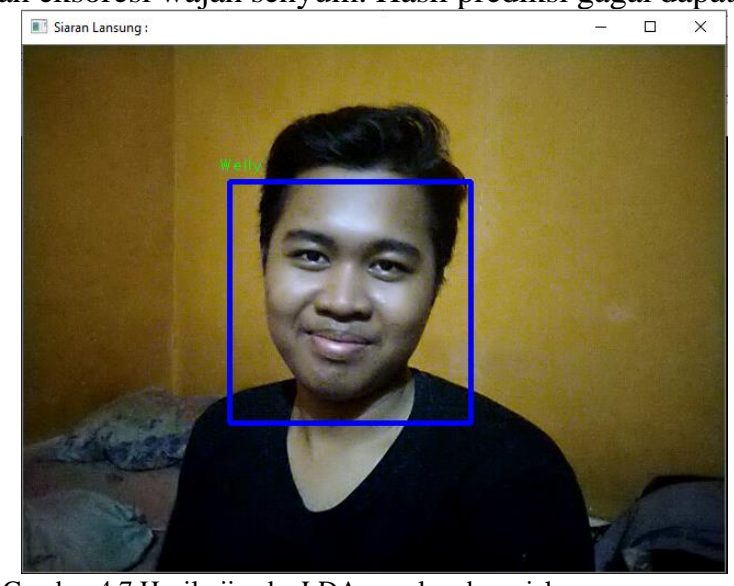

Gambar 4.7 Hasil uji coba LDA gagal pada wajah senyum

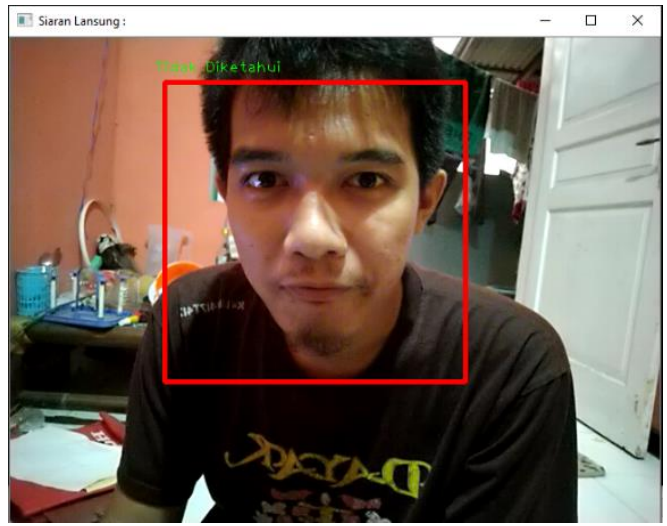

Gambar 4.8 Hasil uji coba LDA berhasil pada wajah senyum 
TABEL 4.5 HASIL PERHITUNGAN AKURASI

\begin{tabular}{|l|l|l|}
\hline Ekstraksi Fitur & PCA & LDA \\
\hline Precision & $82,14 \%$ & $77,78 \%$ \\
\hline Recall & $63,89 \%$ & $58,33 \%$ \\
\hline Accuracy & $98,06 \%$ & $97,73 \%$ \\
\hline
\end{tabular}

Dari hasil pengujian antara ekstraksi fitur PCA dan LDA, berdasarkan perhitungan akurasi pada tabel 4.8 tingkat akurasi yang dihasilkan oleh ekstraksi fitur PCA lebih tinggi daripada LDA. Namun, meskipun hasil akurasi tidak signifikan, hasil pengenalan wajah yang diberikan masing-masing ekstraksi fitur berbeda. Seperti pada sampel subjek bernama Noa, hasil pengenalan wajah datar terdeteksi dengan baik di ekstraksi fitur PCA. Tetapi tidak dikenali dengan baik pada ekstraksi fitur LDA dikarenakan subjek mengubah gaya potongan rambutnya. Hasil tersebut menjadikan PCA lebih baik dalam mengenali wajah secara real-time daripada LDA.

\section{Kesimpulan}

Berdasarkan hasil penelitian yang telah dilakukan, dari 9 sampel orang yang diujikan, didapatkan bahwa algoritma Eigenface dengan ekstraksi fitur PCA memiliki Akurasi 98,06\%, sedangkan Eigenface dengan ekstraksi fitur LDA memiliki akurasi 97,73\%. Hal ini terjadi karena PCA dapat mereduksi dimensi citra hingga ke dalam lebih sederhana dibandingkan LDA, membuat PCA memiliki keunggulan pada proses kecepatan mengambil keputusan untuk mengenali wajah di kondisi real time. Berdasarkan hasil akurasi tiap ekstraksi fitur, dapat disimpulkan bahwa PCA memiliki akurasi lebih baik dalam mengenali wajah secara real-time daripada LDA. Dari hasil tersebut, sistem keamanan CCTV dapat di-optimalkan dengan adanya sistem pengenalan wajah eigenface PCA.

\section{UCAPAN TERIMAKASIH}

Terima kasih sebesar-besarnya untuk bapak Fahrudin Mukti Wibowo, S.Kom., M.Eng. selaku dosen pembimbing 1 dan bapak Wahyu Andi Saputra, S.Pd., M.Eng. selaku dosen pembimbing 2 yang telah membimbing pada penelitian ini. 


\section{DAFTAR PUSTAKA}

[1] H. Kurniawan And T. Hidayat, "Perancangan Program Pengenalan Wajah Menggunakan Fungsi Jarak Metode Euclidean Pada Matlab,”Semin. Nas. Apl. Teknol. Inf. 2008 (Snati 2008), Vol. 1907-5022, No. Snati, Pp. 15-18, 2008.

[2] T. Mulyono, K. Adi, And R. Gernowo, "Sistem Pengenalan Wajah Dengan Metode Eigenface Dan Jaringan Syaraf Tiruan ( Jst )," J. Sains, Fak. Sains Dan Mat., Vol. 15, No. 1, Pp. 15-20, 2012.

[3] K. D. Irianto, "Pendeteksi Gerak Berbasis Kamera Menggunakan Opencv Pada Ruangan,” J. Komuniti, Vol. 2, No. 1, Pp. 52-59, 2010.

[4] D. I. Bramantio, E. Susanto, And R. Nugraha, "Perancangan Dan Implementasi Keamanan Pintu Berbasis Design And Implementation Security Door With Face,” E-Proceeding Eng., Vol. 3, No. 1, Pp. 79-83, 2016.

[5] B. Wara, R. Ramadhan, A. N. Jati, And U. A. Ahmad, "Implementasi Eigenface Untuk Pengenalan Wajah Pada Building Security System Berbasis Embedded Implementation Of Eigenface For Face Recognition,” E-Proceeding Eng., Vol. 3, No. 1, Pp. 764770,2016

[6] A. B. S And H. Maulana, "Pengenalan Citra Wajah Sebagai Identifier Menggunakan Metode Principal Component Analysis ( Pca )," J. Tek. Inform., Vol. 9, No. 2, Pp. 166-175, 2016

[7] O. Rizan And Hamidah, "Rancangan Aplikasi Monitoring Kamera Cetv Untuk Perangkat Mobile Berbasis Android," Ti Atma Luhur J. Teknol. Inform. Dan Komput., Vol. 3, No. 1, Pp. 45-51, 2016.

[8] P. B. S. Dodit Suprianto, Rini Nur Hasanah And Abstrak, "Sistem Pengenalan Wajah Secara Real-Time Adaboost, Eigenface Pca \& Mysql,” J. Eeccis, Vol. 7, No. 2, Pp. 179-184, 2013

[9] E. Prasetyo And I. Rahmatun, "Face Recognition System Design With Expression Position And Variation Method Using Eigenface,” J. Univ. Gunadarma, No. January, 2016. 